\title{
Determinants of Users' Intention to Purchase Legal Video Streaming Services: A Comparative Study between Thai and American Consumers
}

\author{
Athapol Ruangkanjanases * \\ Chulalongkorn University, Thailand \\ athapol@cbs.chula.ac.th \\ Siriyakorn Payakka \\ Chulalongkorn University, Thailand \\ siriyakorn-p@outlook.com \\ Dong Man Kim \\ California State University, USA \\ dkim@csusb.edu
}

\begin{abstract}
The purpose of this study is to identify the significant factors influencing the intention of consumers from Thailand and the United States of America to purchase legal video streaming services. This quantitative study used the theory of planned behavior, as well as convenience sampling, to investigate consumers' intention to purchase streaming services based on behavior; the responses were gathered from 400 respondents (200 respondents from Thailand and 200 respondents from the U.S.). Independent variables presumed to affect intention to purchase are product/service attributes, attitude towards behavior, moral judgment, subjective norms, and perceived behavior control. Descriptive analysis, reliability analysis, and stepwise multiple regression analysis were used to analyze the respondents' data. The results show that perceived behavior control affects the purchasing intent of both Thai and American consumers; however, moral judgment affects the purchasing intent of Thai consumers more significantly, while attitude towards behavior has a greater effect on the purchasing intent of American consumers.
\end{abstract}

Keywords: Purchase, Video Streaming, Theory of Planned Behavior

\section{INTRODUCTION}

Digital media has been a disruptive form of entertainment since long before the invention of the smartphone. Companies in the film industry have redesigned their business model by transitioning from physical products to digital ones and generating new revenue streams through a subscription model or through advertising. Today, we know this technology as video streaming technology, where the streaming service provider creates and delivers audio and video over the Internet to customers' devices around the world. Some digital providers use licensing agreements to gain exclusive rights from production studios to distribute content on their site, while some invest in 
production to create their own original content. However, offering unique content is not the ultimate goal of the streaming provider in competing against other competitors in the same market; the direct competitor of this business is not the other video streaming providers, but the pirated content sites that do not pay licensing fees to content creators [1].

Surprisingly, few published studies have been conducted to determine the possible determinants of users' intention to purchase legal video streaming services. This research aims at studying customers' purchasing behavior and identifying the significant factors affecting both Thai and American consumers' willingness to purchase media streaming service packages. This study will provide meaningful insights, as major production studios invest millions of dollars on new services while consumers invest time and money following their favorite TV shows and participating in discussions about new films.

\section{LITERATURE REVIEW}

\subsection{Background of Video Streaming}

Streaming media is a type of Internet content that has the essential characteristic of being able to be played while still in the process of being downloaded [2]. It was first introduced in the early 1990s, starting with audio content, and later developed into providing video content in 1997. Video streaming technology, also known as video on demand, that is used by the streaming services provided today requires no file to be saved onto the user's disk and has ability to be displayed on multiple resolutions (i.e., from $720 p$ to $480 p$ or from $480 p$ to $720 p$, for instance) in real-time without disruption. Streaming technology is now being widely used not just for entertainment purposes but also for educational and business-related purposes. As users' internet bandwidth and computer processing have become more powerful, media recording technology has increased its capability to record, store, and transfer high-resolution pictures over a greater distance. Additionally, portable interconnected devices and data packages have become more affordable. With these changes in technology comes significant disruption; internet video streaming and downloads are beginning to take a larger share of global bandwidth and will grow to more than 82 percent of all consumer internet traffic by 2022 [3].

In terms of software, most Internet access now occurs through smartphones, where a user can simply download an application from the streaming service provider they subscribed to for free and play the content instantly. Additionally, responsive design now allows users of streaming services to play videos on a variety of screen sizes and operating systems. In terms of hardware, many streaming service providers partner with consumer electronics companies to embed their streaming application on internetconnected products to provide ease of access to the user. That being said, users can still enjoy watching streamed content from a big screen device even when there is no preinstalled app available by using a plug-in dongle, pocket streaming devices or streaming media players. These devices connect the user's non-internet television to the Internet and allow them to stream video and music from online services at resolutions up to $4 \mathrm{~K}$ $(4096 \times 2160$ pixels $)$.

\subsection{Legal Video Streaming Services}


Media content such as film and television shows are originally produced and distributed via cable network platforms similar to regular television programming. As with ordinary TV channels, users are free to access content via television access and a cable network; the programs, however, are scheduled and shown as arranged by the channel provider. Video streaming services are a new alternative to these platforms in which the content is distributed through the Internet, usually concurrently with the regular television programming, and customers are able to choose what program to stream from. However, these streaming services are not free to use. Since these services do not generate advertising revenue, the streaming service provider charges the users access fees. Legal streaming providers, such as Netflix, Amazon Prime, Hulu and CBS All Access, pay content owners to stream their content, whereas illegal streaming service providers offer copyrighted content on their sites for free with the purpose of gaining as many viewers and hits to the site as possible. Furthermore, other providers offer similar products but use different means of access, such as pirated video sites that utilize the BitTorrent protocol.

Subscription fees for local legal video streaming services in Thailand and the United States are slightly different, unlike those for providers that are available in both countries. The average subscription for a streaming package in Thailand (e.g. DooNee, HOOQ, iflix, Hollywood HD, Primetime, Monomax) costs \$6 per month, while the average price of a local streaming package in the United States (e.g. CBS All Access, Hulu, Sling TV, HBO Now, Youtube TV) is \$20 per month. However, for providers that are available in both Thailand and the United States (e.g. Amazon Prime, Netflix, HBO Go), the average price is $\$ 8$ per month. Based on GDP per capita data from the year 2017, Thailand has an average monthly income of $\$ 548$, while the United States has an average monthly income of $\$ 4,995$; therefore, when comparing the average income of both countries, a subscription fee costs $1.46 \%$ of a user's average income in Thailand and $0.16 \%$ of a user's average income in the United States.[4]

\subsection{Legal Video Streaming Industry in Thailand}

There are currently 57 million total Internet users accounted for in Thailand, and $5 \%$ of them use on-demand streaming services; however, the majority of the population still watches traditional TV programs on a regular TV set [5]. This could change shortly; the number of users of streaming services is expected to increase as Netflix has recently been aggressively advertising its service in Thailand [6]. The average time Thais spend using the Internet daily is around 9 hours 38 minutes; of this, 4 hours and 3 minutes is spent watching video via broadcasting, streaming, and on-demand on online platform [7]. Additionally, the digital content or over-the-top (OTT) market in Thailand is valued at 11,057.26 million Baht, approximately 600 million Baht of which comes from the video streaming (SVoD) segment [8]. The Thai streaming market originated in 2014, and the first streaming service in Thailand was a domestic provider, Hollywood TV; this was immediately followed by Prime Time. Both of these services operate as a subscription video on demand ( $\mathrm{SVoD}$ ) business model, generating revenue by charging subscription fees from its members. Subsequently, the foreign provider iflix entered the market in 2015, the same year they entered Malaysian and Philippine markets, and Netflix entered the Thai market in 2017.

\subsection{Legal Video Streaming Industry in the United States}


The total population in America that possesses some form of streaming service accounts for 57 percent of the overall population; this number increased from 53 percent from last year [9], [10]. Netflix accounted for more than half of the total users of streaming video online, followed by Amazon Prime and Hulu. Unlike in Thailand, traditional television channels in America offer a streaming platform for audiences to watch their program's full episodes on demand immediately after airing and will grant a limited license to other streaming providers eight days after a program's initial broadcast. The license is usually granted under terms of agreement that the TV companies will only distribute content in the U.S.; however, video streaming service providers such as Netflix, Hulu, and Amazon Prime receive global streaming distribution rights [11]. Additionally, due to streaming rights, TV companies can only provide the five latest episodes of each of their shows available on their platform for free [12].

\section{HYPOTHESES DEVELOPMENT AND RESEARCH MODEL}

Hypotheses in this research are introduced by various aspects of the theory of planned behavior. In 1985, Ajzen's article addressing an individual's intention to perform a certain behavior can be predicted with evaluating of their perceived behavioral control, subjective norms, and attitude towards behavior. Generally, perceived behavior control refers to individual belief whether they can carry out a certain behavior. Subjective norms refer to what others in the society view a certain behavior or action. And attitude towards behavior refers to individual's feeling whether they see this behavior as good or bad.

Ajzen further suggested that attitudes can be developed from belief people hold about an object and by associating the object with a certain attribute, we can form such belief. In other word, each belief links behavior to a certain attribute such as cost incurred by performing a particular behavior. A study of consumers' channel-migrating intention utilizing theory of planned behavior by Pookulangara and Natesan in 2010 examine people intention the use online store by introducing hedonic and utilitarian dimensions to measure attitudinal beliefs toward channel-migration where utilitarian attributes offer practical functionality, whereas hedonic attributes satisfy emotional desires. The study found that hedonic beliefs did not influence the attitude toward channel-migration for both channels. However, utilitarian beliefs significantly influenced the attitudes for both channels; therefore, indicating that shoppers, considering migrating between these two channels, may be influenced by the convenience factor, which poses that the belief that migrating channels will be more efficient [13]. In this case we add product/service attributes to determine whether it has desirable or undesirable consequences [14]. Additionally, since subjective norms only consider outside force that influence an individual to perform a certain behavior we also need to consider inside force or individual feelings of moral obligation. Thus, moral judgement is added to value individual intention to perform or not to perform a certain behavior.

The conceptual framework consists of five independent variables which were presumed to have an impact on user's intention to purchase legal video streaming services in which considered as a dependent variable. The hypotheses were developed based on past empirical evidence and theory found in the research of Phau Ian, Liang Johan, Lwin Michael (2014) which were later referred to and developed by Natthapong Inpo (2015) and Riza Casidy (2015) by focusing on attitude toward legal online video 
streaming services, moral judgement, social habit and self-efficacy. Interestingly, Inpo research found that all three aspects of theory of planned behavior has an influence on customer's purchasing decision.

\subsection{Product/Service Attributes}

Product and service attributes refer to features that a provider offers. These features can be the quality and/or value of the product or service. In 2016 Wenzel et al. published a paper in which they investigated leading video streaming service providers such as Netflix, Hulu, and Amazon Prime and how they offer their services. The study found that Netflix focuses on smart, convenient and easy service to customers while Amazon focuses on good value and a large selection of content.

Hypothesis 1A (H1A). The attributes of a legal video streaming service have an effect on intention to purchase a legal video streaming service for Thais.

Hypothesis 1B (H1B). The attributes of a legal video streaming service have an effect on intention to purchase a legal video streaming service for Americans.

\subsection{Moral Judgment}

In 2006, Al-Rafee, and Cronan published their historically significant journal on digital piracy, which described how an individual is subject to moral obligation, referring to the feeling of guilt or a person's obligation to perform or not to perform a behavior [15]. Later P. Ian, L. Aaron, L. Johan, and L. Michael (2014) performed an investigation on the same topic, but referred to a theory of planned behavior approach in which the results confirmed that moral judgment, social habits and self-efficacy are an appropriate means to evaluate an individual's intentions to engage in digital piracy [16].

Hypothesis 2A (H2A). Moral judgment has an effect on intention to purchase legal video streaming service for Thais.

Hypothesis 2B (H2B). Moral judgment has an effect on intention to purchase legal video streaming service for Americans.

\subsection{Perceived Behavioral Control}

In 1986, Ajzen and Madden pointed out that perceived behavior control refers to the perceived ease or difficulty of performing a behavior [17]. One study by G.E. Higgins examined the area of self-control in the context of digital piracy and found that individuals with low self-control are more likely to engage in digital piracy and less likely to purchase a legal video streaming service. On the other hand, individuals with high self-control are more likely to resist using an illegal service [18].

Hypothesis 3A (H3A). Perceived behavioral control has an effect on intention to purchase legal video streaming service for Thais.

Hypothesis 3B (H3B). Perceived behavioral control has an effect on intention to purchase legal video streaming service for Americans. 


\subsection{Subjective Norms}

A detailed examination of the theory of planned behavior by Ajzen in 1991 described subjective norms as the "perceived social pressure to perform or not to perform the behavior" [19]. Based on research on the effect of social influence towards willingness to purchase online by Chin, Wafa, and Ooi in 2009, social pressure or social influence have a positive influence on an individual's willingness to purchase online [20].

Hypothesis 4A (H4A). Social influence has an effect on intention to purchase legal video streaming service for Thais.

Hypothesis 4B (H4B). Social influence has an effect on intention to purchase legal video streaming service for Americans.

\subsection{Attitudes toward Behaviors}

In the previously listed research by Chin et.al, attitudes towards behavior were related to "a person's favorable or unfavorable assessment regarding the behavior in question" [21]. A recent study by Laghari, Issa, Speranza, and Falk involved Qualityof-Experience (QoE) regarding human perception, feelings, needs and intention to assess the performance of a multimedia application [22]. Such attitudes have been found to have an effect on the intent to engage in digital piracy [23], [24].

Hypothesis 5A (H5A). Attitudes toward legal video streaming service have an effect on intention to purchase legal video streaming service for Thais.

Hypothesis 5B (H5B). Attitudes toward legal video streaming service have an effect on intention to purchase legal video streaming service for Americans.

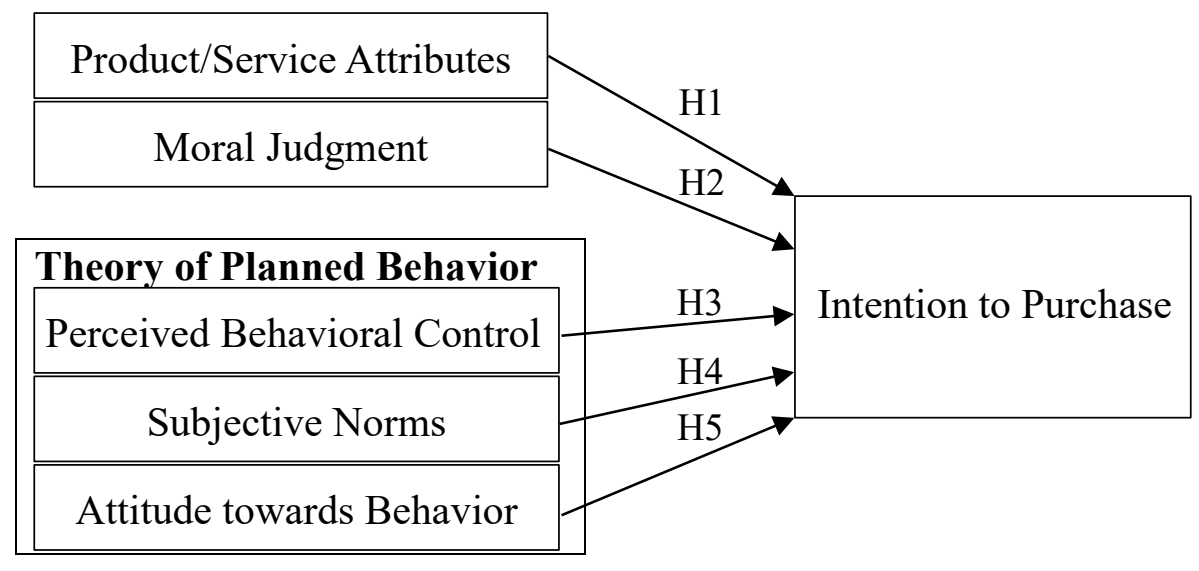

Figure 1. Conceptual model

As shown in figure 1, the conceptual model consists of five independent variables, namely product/service attributes, moral judgment, perceived behavioral control, subjective norms, and attitude towards behavior. The dependent variable is the intention to purchase legal streaming video services. 


\section{METHODOLOGY}

\subsection{Samples and Data Collection}

There are currently 57 million internet users in Thailand, $5 \%$ of which $(2,850,000)$ use an on-demand streaming service. In the United States, there are currently $163,533,000$ consumers of this service. Using a 95 percent confidence level with sampling error of 5 percent based on Yamane, the sample size of the respondents consisted of 400 consumers who has experiences using a streaming services. The researchers used quota sampling for data collection; half of the samples were from Thai respondents, and the rest of the samples were from American respondents. An online survey questionnaire was developed to test hypotheses in this research and distributed during August to December 2018. A screening question was set as the first question in the questionnaire to confirm that each respondent has experiences in using a streaming service. A total of 400 completed questionnaires were returned; 200 Thai and 200 American who have experience using a streaming service.

Table 1. Demographic profile

\begin{tabular}{lllll}
\hline Demographic profile & American & Thai & \\
\hline Gender & Number & Percentage & Number & Percentage \\
Male & 99 & 49.5 & 64 & 32.0 \\
Female & 101 & 50.5 & 136 & 68.0 \\
Age & & & & \\
Baby boomer (>54 years old) & 7 & 3.5 & 11 & 5.5 \\
Generation X (38-55 years old) & 29 & 14.5 & 19 & 9.5 \\
Generation Y (22- 37 years old) & 127 & 63.5 & 146 & 73.0 \\
Generation Z (<21 years old) & 37 & 18.5 & 24 & 12.0 \\
Education & & & & \\
High School or below & 74 & 37.0 & 10 & 5.0 \\
Associate Degree & 27 & 13.5 & 3 & 1.5 \\
Bachelor Degree & 70 & 35.0 & 155 & 77.5 \\
Master Degree & 19 & 9.5 & 32 & 16.0 \\
Ph.D. Degree & 10 & 5.0 & 0 & 0 \\
Marital status & & & & \\
Single & 138 & 69.0 & 148 & 74.0 \\
Married with child(ren) & 33 & 16.5 & 30 & 15.0 \\
Married without children & 19 & 9.5 & 20 & 10.0 \\
Separated & 2 & 1.0 & 0 & 0 \\
Divorced & 8 & 4.0 & 2 & 1.0 \\
\hline
\end{tabular}

\subsection{Research Instrument and Variable Measurement}

Thirty-three questions were used to measure the five independent variables and five questions were used to measure the dependent variable. Aside from demographic profiles, all items were measured on a five-point Likert Scale ranging from 1 (strongly disagree) to 5 (strongly agree). A sample questionnaire is included in Appendix A. 


\subsection{Reliability}

The reliability of the questionnaire was tested using Cronbach's alpha. Table 1 shows that the reliability coefficients of all independent variables are above 0.70 . Therefore, the items used to measure the constructs are reliable.

Table 2. Reliability Analysis

\begin{tabular}{lc}
\hline Variable & Cronbach's alpha \\
\hline Product/Service Attributes & .909 \\
Moral Judgment & .838 \\
Perceived Behavioral Control & .778 \\
Subjective Norms & .874 \\
Attitude towards Behavior & .719 \\
\hline
\end{tabular}

\subsection{Validity}

Factor analysis with varimax rotation was applied to test the validity of the constructs. An extracted fixed number of six factors were applied. The results in Table 2 confirm the existence of factors with eigenvalues greater than 1.0, and all items have a factor loading of more than 0.50 . These results confirm that each of these constructs is unidimensional and factorially distinct, and that all items used to operationalize the particular construct are loaded onto a single factor.

Table 3. Factor Analysis

\begin{tabular}{lcccc}
\hline \multicolumn{1}{c}{ Construct } & $\begin{array}{c}\text { No. } \\
\text { of } \\
\text { items }\end{array}$ & $\begin{array}{c}\text { Factor } \\
\text { loading }\end{array}$ & Eigenvalues & $\begin{array}{c}\text { Percentage of } \\
\text { variance }\end{array}$ \\
\hline roduct/Service Attributes & 15 & $.471-.835$ & 8.865 & 22.730 \\
Ioral Judgment & 5 & $.705-.793$ & 5.218 & 36.109 \\
arceived Behavioral Control & 6 & $.474-.784$ & 2.102 & 49.641 \\
ubjective Norms & 3 & $.739-.831$ & 1.767 & 54.172 \\
ttitude towards Behavior & 3 & $.625-.714$ & 1.656 & 58.417 \\
\hline
\end{tabular}

\section{DATA ANALYSIS}

The Statistical Package for the Social Sciences (SPSS) was used to analyze primary data collected from questionnaires in this study.

\subsection{Descriptive Statistics}

Descriptive statistics of samples on demographic data are shown in Table 1. The results show that the majority of the American samples are single females in Generation $\mathrm{Y}$ with a high school or below level of education, while Thai samples mostly consisted of single females in Generation Y with a bachelor's degree in education.

\subsection{T-Test Analysis}

As shown in Table 4, the mean scores of the variables product/service attribute, moral judgment, subjective norms, and perceived behavior control for Thai respondents were significantly different from the mean scores of the American respondents since their p-value was less than 0.05. Alternatively, attitude towards behavior and intention 
to purchase had a p-value of more than 0.05 , which means the variability between the two countries were not significantly different in that regard.

Table 4. T-Test

\begin{tabular}{|c|c|c|c|c|c|c|c|c|}
\hline & \multirow[b]{2}{*}{$\mathrm{F}$} & \multirow[b]{2}{*}{ Sig. } & \multirow[b]{2}{*}{$\mathrm{t}$} & \multirow[b]{2}{*}{$\mathrm{df}$} & \multirow{2}{*}{$\begin{array}{c}\text { Mean } \\
\text { Difference }\end{array}$} & \multirow{2}{*}{$\begin{array}{l}\text { Std. Error } \\
\text { Difference }\end{array}$} & \multicolumn{2}{|c|}{$95 \%$ Conf Interval of Diff } \\
\hline & & & & & & & Lower & Upper \\
\hline \multirow[t]{2}{*}{$\mathrm{P} / \mathrm{SA}$} & 66.831 & .000 & -13.925 & 398 & -.907 & .065 & -1.035 & -.778 \\
\hline & & & -13.925 & 289.529 & -.907 & .065 & -1.035 & -.778 \\
\hline \multirow[t]{2}{*}{ ATB } & 2.268 & .133 & -1.351 & 398 & -.092 & .068 & -.225 & .042 \\
\hline & & & -1.351 & 389.640 & -.092 & .068 & -.225 & .042 \\
\hline \multirow[t]{2}{*}{$\overline{\mathrm{MJ}}$} & 12.584 & .000 & -4.015 & 398 & -.326 & .081 & -.485 & -.166 \\
\hline & & & -4.015 & 383.611 & -.326 & .081 & -.485 & -.166 \\
\hline \multirow[t]{2}{*}{$\mathrm{SN}$} & 3.884 & .049 & -5.976 & 398 & -.583 & .098 & -.775 & -.391 \\
\hline & & & -5.976 & 389.120 & -.583 & .098 & -.775 & -.391 \\
\hline \multirow[t]{2}{*}{$\overline{\mathrm{PBC}}$} & .005 & .942 & -3.063 & 398 & -.183 & .059 & -.301 & -.065 \\
\hline & & & -3.063 & 396.648 & -.183 & .059 & -.30 & -.065 \\
\hline \multirow[t]{2}{*}{ ITP } & .466 & .495 & .240 & 398 & .015 & .062 & -.108 & .138 \\
\hline & & & .240 & 390.629 & .015 & .062 & -.108 & .138 \\
\hline
\end{tabular}

\subsection{Correlation Analysis}

Correlation analysis was used to test for any multicollinearity that might exist among the five variables. As shown in Table 5 and Table 6, moral judgment has the strongest correlation to intention to purchase legal video streaming services, at 0.477 for Thai respondents, and perceived behavioral control has the strongest correlation to intention to purchase legal video streaming services, at 0.503 for American respondents.

Table 5. Correlation among variables for Thai consumers

\begin{tabular}{lcccccc}
\hline Variables & PSA & ATB & MJ & SN & PBC & IP \\
\hline Product/Service Attributes & 1 & .017 & .479 & .030 & .353 & .355 \\
Moral Judgment & & 1 & .101 & .512 & .410 & .477 \\
Perceived Behavioral Control & & & 1 & .106 & .359 & .429 \\
Subjective Norms & & & & 1 & .324 & .129 \\
Attitude towards Behavior & & & & & 1 & .274 \\
Intention to Purchase & & & & & & \\
\hline
\end{tabular}

*Significant level at 0.05

Table 6. Correlation among variables for American consumers.

\begin{tabular}{lcccccc}
\hline Variables & PSA & ATB & MJ & SN & PBC & IP \\
\hline Product/Service Attributes & 1 & .100 & .066 & .209 & .167 & .038 \\
Moral Judgment & & 1 & .287 & .388 & .326 & .337 \\
Perceived Behavioral Control & & & 1 & .120 & .456 & .503 \\
Subjective Norms & & & & 1 & .142 & .212 \\
Attitude towards Behavior & & & & & 1 & .379 \\
Intention to Purchase & & & & & & 1 \\
\hline
\end{tabular}

*Significant level at 0.05

\subsection{Collinearity Diagnostics Tests}

A collinearity diagnostic test was performed to check for multicollinearity. By referring to A Caution Regarding Rules of Thumb for Variance Inflation Factors, O'Brien [25] suggests that a tolerance score of less than 0.2 would contribute to 
multicollinearity. As shown in tables 7 and 8 , the tolerance values are greater than 0.2 for both Thai and American respondents. This indicates there is no multicollinearity among the variables.

Table 7. Collinearity statistics of Thai consumers

\begin{tabular}{lc}
\hline & Collinearity statistics \\
\cline { 2 - 2 } Variables & Tolerance \\
\hline Product/Service Attributes & .714 \\
Moral Judgment & .661 \\
Perceived Behavioral Control & .732 \\
Subjective Norms & .721 \\
Attitude towards Behavior & .672 \\
\hline
\end{tabular}

Table 8. Collinearity statistics of American consumers.

\begin{tabular}{lc}
\hline & Collinearity statistics \\
\cline { 2 - 2 } Variables & Tolerance \\
\hline Product/Service Attributes & .936 \\
Moral Judgment & .757 \\
Perceived Behavioral Control & .770 \\
Subjective Norms & .820 \\
Attitude towards Behavior & .736 \\
\hline
\end{tabular}

\subsection{Stepwise Multiple Regression Analysis and Hypothesis Test}

From Table 9, four variables appear to have a significant impact on intention to purchase for Thai consumers, which are product/service attributes $(\beta=0.211, \mathrm{p}=$ $0.001)$, moral judgment $(\beta=0.538, p=0.000)$, perceived behavioral control $(\beta=0.293$, $\mathrm{p}=0.000)$, and subjective norms $(\beta=-0.183, \mathrm{p}=0.004)$. The adjusted $\mathrm{R}^{2}$ is at 0.422 , which means that the three predictors could explain $42.2 \%$ of the variance of the dependent variable (intention to purchase).

As illustrated in Table 10, three variables appear to have a significant impact on the intention to purchase for American consumers, which are moral judgment $(\beta=0.180$, $\mathrm{p}=0.005)$, perceived behavioral control $(\beta=0.385, \mathrm{p}=0.000)$, and attitude towards behavior $(\beta=0.145, p=0.036)$. The adjusted $\mathrm{R}^{2}$ is at 0.299 , which means that the three predictors could explain $29.9 \%$ of the variance of the dependent variable (intention to purchase).

In conclusion, the factors influencing intention to purchase a legal video streaming service by Thai consumers is shown in Figure 2 and the factors influencing intention to purchase a legal video streaming service by American consumers is shown in Figure 3. 
Table 9. Stepwise multiple regression for Thai consumers

\begin{tabular}{|c|c|c|c|c|c|c|c|c|c|}
\hline & Variables & B & $\beta$ & $\mathrm{t}$ & Sig. & $\mathrm{R}$ & $\mathrm{R}^{2}$ & $\begin{array}{l}\text { Adj. } \\
\mathrm{R}^{2}\end{array}$ & $\begin{array}{c}\text { Overal } \\
1 \mathrm{~F}\end{array}$ \\
\hline \multirow{5}{*}{$\begin{array}{c}\text { Criterion } \\
: \\
\text { Predictor } \\
:\end{array}$} & $\begin{array}{l}\text { Intention to } \\
\text { Purchase }\end{array}$ & & & & & \multirow[t]{5}{*}{$\begin{array}{c}.65 \\
8\end{array}$} & \multirow[t]{5}{*}{.434} & \multirow[t]{5}{*}{.422} & \multirow[t]{5}{*}{37.307} \\
\hline & $\begin{array}{l}\text { Product/Servi } \\
\text { ce Attribute }\end{array}$ & .302 & .211 & 3.437 & $\begin{array}{c}.00 \\
1\end{array}$ & & & & \\
\hline & $\begin{array}{l}\text { Moral } \\
\text { Judgement }\end{array}$ & .428 & .538 & 8.558 & $\begin{array}{c}.00 \\
0\end{array}$ & & & & \\
\hline & $\begin{array}{l}\text { Perceived } \\
\text { Behavioral } \\
\text { Control }\end{array}$ & .293 & .293 & 4.728 & $\begin{array}{c}.00 \\
0\end{array}$ & & & & \\
\hline & $\begin{array}{l}\text { Subjective } \\
\text { Norms }\end{array}$ & $\begin{array}{c}-.11 \\
8\end{array}$ & -.183 & -2.92 & $\begin{array}{c}.00 \\
4\end{array}$ & & & & \\
\hline
\end{tabular}

Table 10. Stepwise multiple regression for American consumers

\begin{tabular}{|c|c|c|c|c|c|c|c|c|c|}
\hline & Variables & B & $\beta$ & $\mathrm{t}$ & Sig. & $\mathrm{R}$ & $\mathrm{R}^{2}$ & $\begin{array}{l}\text { Adj. } \\
R^{2}\end{array}$ & $\begin{array}{c}\text { Overall } \\
\mathrm{F}\end{array}$ \\
\hline \multirow{3}{*}{ Criterion: } & Intention & & & & & \multirow{8}{*}{.556} & & \multirow{8}{*}{.299} & \multirow{8}{*}{29.243} \\
\hline & to & & & & & & .309 & & \\
\hline & Purchase & & & & & & & & \\
\hline \multirow[t]{5}{*}{ Predictor: } & $\begin{array}{l}\text { Moral } \\
\text { Judgement }\end{array}$ & .135 & .180 & 2.822 & .005 & & & & \\
\hline & Perceived & & & & & & & & \\
\hline & Behavioral & .417 & .385 & 5.699 & 0 & & & & \\
\hline & Control & & & & & & & & \\
\hline & $\begin{array}{l}\text { Attitude } \\
\text { towards } \\
\text { Behavior }\end{array}$ & .154 & .145 & 2.110 & .036 & & & & \\
\hline
\end{tabular}

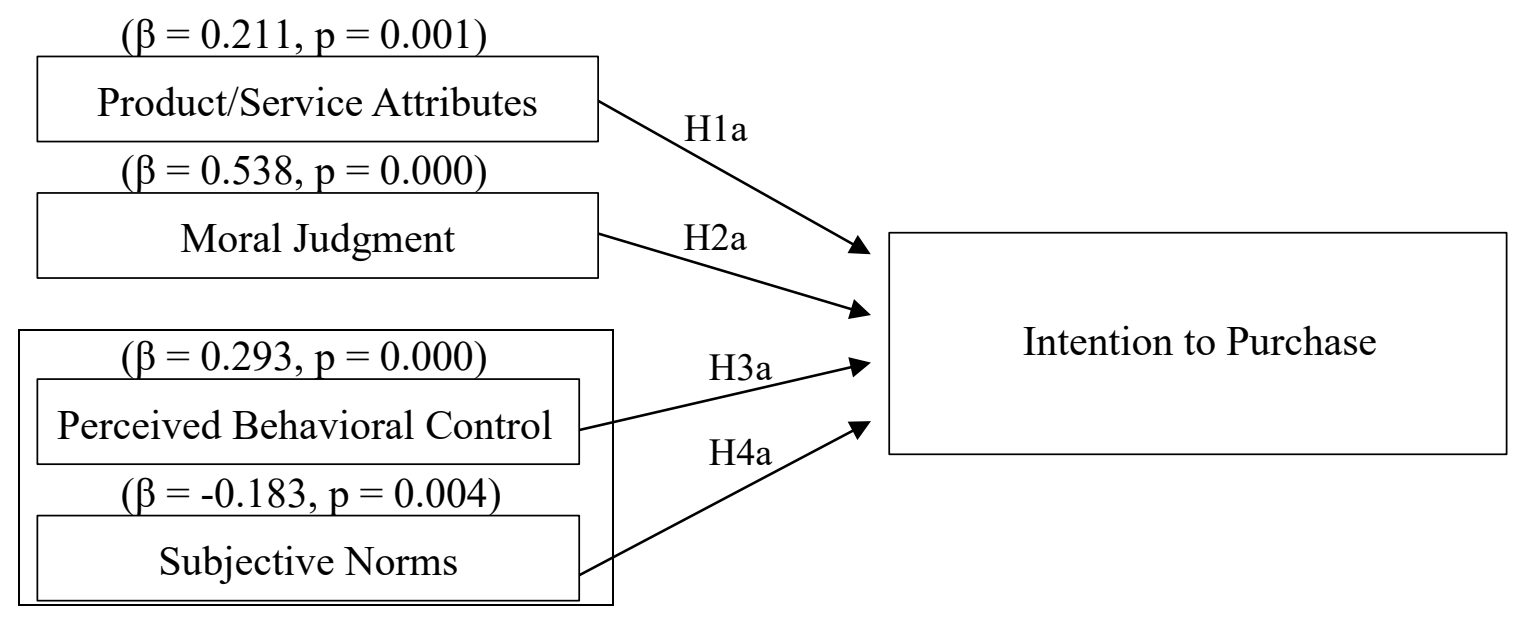

Figure 2. Multiple regression for Thai consumers 


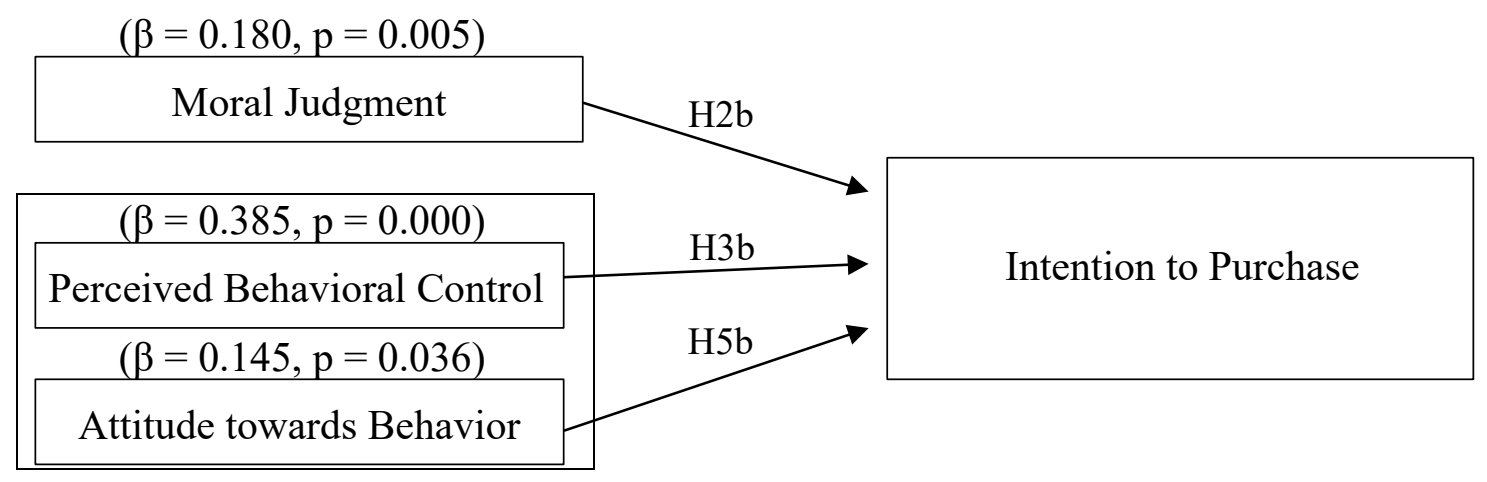

Figure 3. Multiple regression for American consumers

\section{CONCLUSIONS}

The results show that product/service attributes have an influence on Thai customers because Thai customers appreciate the quality of the product and its value for money. This also reflects that service providers in Thailand tend to offer mainstream, well-known movies or TV series rather than promoting unique and original content like providers in the United States. This result could be interpreted that attitude towards behavior has an influence on American customers because American customers tend to appreciate the user experience more than product quality and value; examples can be seen in the features that each provider offers in their platform. Most providers in the United States use techniques like efficient browsing capabilities, consumer-friendly user interfaces powered by personalization and live support chat to promote the user experience, unlike providers in Thailand that are less concerned with the aforementioned features. Subjective norms' influence on Thai customers could be evidence of Thailand's culture of restraint. Referring to Hofstede's cultural dimensional theory, people in restraint cultures tend to be influenced by social pressure over individual desires; this contrasts with an indulgence culture, like the United States, where people have more freedom over the way an individual achieves its individual desires.

In the study, moral judgment and perceived behavioral control influenced both Thai and American consumers to a similar extent, which could suggest that consumers tend to purchase a legal video streaming service based on an individual's cognitive judgment on what particular behaviors the individual considers as acceptable and favorable.

However, one significant difference between Thai consumers and American consumers is that product/service attributes and subjective norms are significant factors for Thai consumers, while attitude towards behavior is a significant factor for American consumers. This could reveal that Thai consumers are pragmatic, seek flexibility and prefer products that are socially accepted instead of seeking and trying new products on their own. American consumers, influenced by the attitude towards behavior factor, 
prefer to use their needs and interests to support their purchasing decision and therefore purchase a product based on their own judgment.

It is recommended that further research be undertaken to explore additional possible factors that could influence the purchasing intention of legal video streaming services. As video streaming services and video-on-demand services are relatively novel for Thai consumers, in-depth interviews could be conducted to ensure data validity and be used to adjust and redesign the survey questionnaire.

\section{APPENDIX A. QUESTIONAIRE}

All questions were assessed on a five-point Likert scale ranging from 1 (strongly disagree) to 5 (strongly agree).

\section{Product/Service Attributes}

1. I am concerned with the audio quality.

2. I am concerned with the video quality.

3. I am concerned with the resume at last play.

4. I am concerned with the multi-devices access.

5. I am concerned with the price.

6. I am concerned with the playback speed.

7. I am concerned with the number of contents.

8. I am concerned with the content categorization.

9. I am concerned with the download to watch offline.

10. I am concerned with the freshness of contents.

11. I am concerned with the free-trial period.

12. I am concerned with the subtitle of my native language.

13. I am concerned with the account sharing.

14. I am concerned with the bundling plan with free Internet from mobile operators.

15. I am concerned with the recommendation system.

16. I am concerned with the uniqueness of contents.

\section{Moral Judgement}

1. I think it is wrong to use illegal video streaming services that did not pay license for the content they acquired.

2. I think I should support people involved in creating the content by using legal streaming services.

3. I feel guilty to using illegal video streaming services.

4. I think using legal video streaming services is ethical.

5. I encourage people to use legal video streaming services.

\section{Perceived Behavioral Control}

1. It is easy to select dubbed audio of my native language and the original soundtrack.

2. It is easy to select subtitle of my native language and the original language.

3 . It is easy to select the quality of the video.

4. It is easy to resume the video at where I left.

5. It is easy to download videos from legal video streaming services to watch offline. 
6. It is easy to watch videos and switch across my devices.

\section{Subjective Norms}

1. My colleagues encourage me to purchase legal video streaming services.

2. My friends encourage me to purchase legal video streaming services.

3. My family encourages me to purchase legal video streaming services.

\section{Attitude and Behavior}

1. I like legal video streaming services because video resolution can adapt to my Internet speed without buffering or skips.

2. I like legal video streaming services because there are no advertisement interrupts when I stream a content.

3. I like legal video streaming services because there are a lot of contents.

\section{Intention to Purchase}

1. I would like to see more content from this legal video streaming service.

2. My willingness to buy from legal video streaming service in the future is high.

3. I think legal video streaming services provide the best streaming experience.

4. I think using legal video streaming services is value for money.

5. It is easy to purchase the legal video streaming services.

\section{REFERENCES}

[1] Digital Age Magazine, Video Streaming [online]. Available: https://www.digitalagemag.com/video-streaming.

[2] A. Gelman, S. Halfin, W. Willinger, "On buffer requirements for store-andforward video on demand service circuits", in IEEE Global Telecommunications Conference GLOBECOM '91: Countdown to the New Millennium, 1991, pp. 976980.

[3] Cisco VNI. (2018, 8, 18). Cisco Visual Networking Index: Forecast and Trends, 2017-2022 White Paper [Online]. Available: https://www.cisco.com/c/en/us/solutions/collateral/service-provider/visualnetworking-index-vni/white-paper-c11-741490.html.

[4] Digital in Asia (2018) [Online]. Available: https://digitalinasia.com/2018/01/31/latest-digital-in-2018-global-report/

[5] S. Funk (2018, 8, 22). Digital in Southeast Asia \& Thailand 2018[Online]. Available: https://my-thai.org/digital-southeast-asia-thailand-2018/.

[6] Datareportal, Digital in Thailand (2018) [online]. Available: https://datareportal.com/digital-in-thailand.

[7] Statista, Video Streaming (SVoD) Thailand (2018) [online]. Available https://www.statista.com/outlook/dmo/digital-media/video-on-demand/videostreaming-svod/Thailand.

[8] S. Liesman $(2018,7,18)$. Nearly $60 \%$ of Americans are streaming and most with Netflix [Online]. Available: https://www.cnbc.com/2018/03/29/ nearly-60percent-of-americans-are-streaming-and-most-with-netflix-cnbc-survey.html. 
[9] D. Kaufman $(2018,9,22)$. Netflix Remains No. 1, But Faces Increasing OTT Competition[Online]. Availabe: http://www.etcentric.org/netflix-remains-no1-but-faces-increasing-ott-competition/.

[10] S. Patelv $(2018,8,04)$. Netflix's deal terms pose a conundrum for TV studios. Retrieved[Online]. Available: https://digiday.com/media/netflixs-deal-terms pose-a-conundrum-for-tv-studios/.

[11] The CW Television Network $(2018,7,25)$. Why aren't all episodes of my favorite CW shows available? [Online]. Available: https://support.cwtv.com/hc/ en-us/articles/218172983-Why-aren-t-all-episodes-of-my-favorite-CW-showsavailable-.

[12] P. Wenzel, I. Mahle, and J. U. Pätzmann, "Streaming services \& service design: an analysis of netflix and amazon video based on the gap model by parasuraman", Berry \& Zeithaml, Markenbrand, 5, pp. 20-31, 2016.

[13] S. Pookulangara, P. Natesan., "Examining consumers' channel-migrating intention utilizing theory of planned behavior: A Multigroup Analysis, ", International Journal of Electronic Commerce Studies, Vol.1, No.2 , pp. 97-116, 2010.

[14] I. Ajzen, The theory of planned behavior, Organizational Behavior and Human Decision Process, Vol. 50, pp. 179-211, 1991.

[15] S. Al-Rafee and T.P. Cronan, "Digital piracy: factors that influence attitude toward behavior," Journal of Business Ethics, Vol. 63, No. 3, pp. 237-259, 2006.

[16] P. Ian, L. Aaron, L. Johan, and L. Michael (2014), "Engaging in digital piracy of movies: a theory of planned behaviour approach," Internet Research [online], Vol. 24, No. 2, pp. 246-266. Available: https://doi.org/10.1108/IntR-11-2012-0243.

[17] I. Ajzen and T.J. Madden, "Prediction of goal-directed behavior: attitudes, intentions, and perceived behavioral control," Journal of Experimental Social Psychology, Vol. 22, No. 5, pp. 453-474, 1986.

[18] G.E. Higgins, "Digital piracy, self-control theory, and rational choice: an examination of the role of value," International Journal of Cyber Criminology, Vol.1, No.1, pp. 33-55, 2007.

[19] I. Ajzen, "The theory of planned behavior. Organizational Behavior and Human Decision Processes," Vol. 50, No. 2, pp. 179-211, 1991.

[20] A.J. Chin, S.A. Wafa, and A.Y. Ooi, "The effect of internet trust and social influence towards willingness to purchase online in Labuan, Malaysia," International Business Research, Vol. 2, No. 2, pp. 72-81, 2009.

[21] K. Laghari, O. Issa, F. Speranza, and T.H. Falk, "Quality-of-experience perception for video streaming services: Preliminary subjective and objective results," Proceedings of Signal and Information Processing Association Annual Summit and Conference, pp. 1-9, 2012.

[22] A.G. Peace, D.F. Galletta, and J.Y. Thong. (2014, 12). "Software piracy in the workplace: A model and empirical test". Journal of Management Information Systems [Online], Vol. 20, No. 1, pp. 153-177, 2003. Available: https://www.tandfonline.com/doi/abs/10.1080/07421222.2003.11045759.

[23] M. Limayem, M. Khalifa, and W. Chin, "Factors Motivating Software Piracy: A Longitudinal Study," IEEE Transactions on Engineering Management, Vol. 51, No. 4, pp. 414-425, 2004.

[24] T.P. Cronan, and S. Al-Rafee, "Factors that influence the intention to pirate software and media," Journal of Business Ethics, Vol. 78, No. 4, p 527-545, 2008.

[25] R.M. O'Brien, "A caution regarding rules of thumb for variance inflation factors," Quality and Quantity, Vol. 41, pp. 673-690, 2007. 
